\title{
CORRESPONDENCE
}

\section{Lessons learnt in the anaesthetic management of a neonate with giant occipital meningomyelocoele}

\section{Arun K. Gautham, Ramamani Mariappan, Georgene Singh}

A 25-day-old full-term neonate born by lower segment caesarean section presented with $14 \mathrm{~cm} \times 12 \mathrm{~cm}$ mass on the back of the neck. The baby was antenatally diagnosed to have occipital meningomyelocoele. Computed tomography head taken after birth showed communicating hydrocephalus and enlarged posterior fossa with hypoplastic cerebellar hemispheres.

On examination, the child weighed $3.6 \mathrm{~kg}$ and was lying in right lateral position because of the mass size. The child had a short, webbed neck with torticollis towards the right. The head was in flexed position with limited neck extension. Respiratory and cardiovascular examination was unremarkable. There was no neurological deficit and the baby was feeding well. Pre-operative investigations were within normal limit.

The child was posted for left-sided ventriculoperitoneal (VP) shunt followed by meningomyelocoele excision. The baby was fasted for $4 \mathrm{~h}$ for breast milk and water for $2 \mathrm{~h}$. No premedication was given. Fifty millilitres of packed cell and $50 \mathrm{ml}$ of fresh frozen plasma were arranged for intraoperative use. Difficult airway, positioning during intubation and surgery, temperature, fluid and haemodynamic management were the anticipated potential challenges.

The child's head was positioned in Maquet pillow in lateral position and meningocele was carefully positioned into the depression of the Maquet pillow [Figure 1a]. The trunk was elevated with the piece of operating table cushion [Figure 1b].

Department of Anaesthesia, Christian Medical College, Vellore, Tamil Nadu, India

Address for correspondence:

Dr. Ramamani Mariappan, Department of Anaesthesia, Christian

Medical College, Vellore, Tamil Nadu, India.

E-mail: ramamani@cmcvellore.ac.in

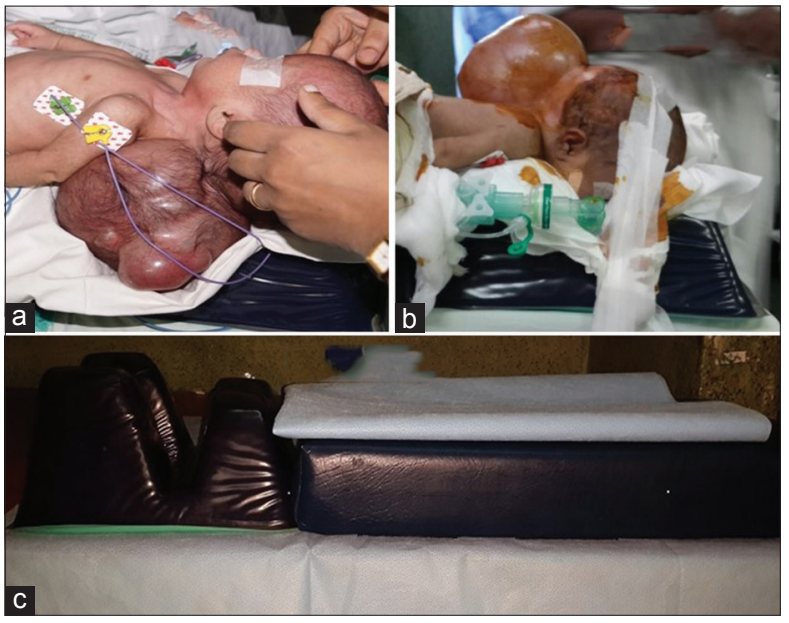

Figure 1: (a) Neonate is positioned supine on a Maquet pillow. (b) The Maquet pillow and the part of an operating table cushion are aligned together to elevate the neonate's trunk. (c) Neonate is positioned prone on a Maquet pillow for meningocele excision

After attaching the standard monitors (electrocardiogram, pulse oximetry and non-invasive blood pressure), the child was induced with increasing concentration of sevoflurane (dial setting 1\%-4\%) and 100\% oxygen. Once the child was taken deep with sevoflurane, a 24-gauge peripheral intravenous cannula was established in the right upper limb. Glycopyrrolate $(0.04 \mathrm{mg})$ and fentanyl $(2 \mathrm{mcg} / \mathrm{kg})$ and propofol $(10 \mathrm{mg})$ were given and the mask ventilation was considered adequate. Laryngoscopy was attempted with MAC 1 blade without the neuromuscular blockade in the lateral position. The Cormack-Lehane scopy grade was 4 . The ventilation became difficult after the first laryngoscopy; hence, we had decided to paralyse the child with atracurium $(0.5 \mathrm{mg} / \mathrm{kg})$ after which the ventilation became better. A repeat attempt of the laryngoscopy with Miller blade in right lateral position also failed to improve the scopy grade and the intubation attempt was unsuccessful. Both attempts of laryngoscopy were very quick and we could ventilate the child in between the laryngoscopy and there was no desaturation noted during this time.

Since the prior attempts at laryngoscopy in lateral position failed, the intubation was attempted in supine using a glidescope after lifting the baby in the air by three assistants. In this position, with optimal external laryngeal manipulation, the laryngoscopy grade improved to grade 3B. A $3.5 \mathrm{~mm}$ endotracheal tube (ETT) was introduced, which could not be passed beyond the cricoid ring. The tube was kept in that place and the child was ventilated for few minutes. Then, with the help of paediatric bougie, the ETT was exchanged to $3 \mathrm{~mm}$ size and was fixed at $10 \mathrm{~cm}$ at the mouth. Intubation was confirmed clinically by auscultation and end-tidal $\mathrm{CO}_{2}$. To prevent ETT kink in prone position, the tube was 
reinforced with $4.0 \mathrm{~mm}$ ETT. The technique of reinforcing the smaller size ETT has been described by Singh et al ${ }^{[1]} \mathrm{As}$ per this technique, the $4 \mathrm{~mm}$ ETT was cut short at $12 \mathrm{~cm}$ and then was slit longitudinally along the blue line and was encircled over a $3.0 \mathrm{~mm}$ ETT. The outer tube covered the inner tube from a cm above the glottic opening to ETT connector. The child was positioned in supine oblique on a Maquet pillow for VP shunt. Anaesthesia was maintained with air, oxygen and sevoflurane and intermittent doses of fentanyl. Once the VP shunt was done, the child was proned for meningocele excision. Head was positioned on a Maquet pillow and the soft jelly roll was placed below the chest and the hip leaving the abdomen free [Figure 1c]. Pressure points were checked and padded adequately.

Intraoperatively, the temperature, haemodynamics, electrolytes and sugar were maintained within normal limits. Blood loss and fluid loss from meningocele excision were replaced with $50 \mathrm{ml}$ of FFP and $60 \mathrm{ml}$ of blood. At the end of the procedure, the child was reversed and extubated fully awake and there was no neurological deficit. Postoperatively, the child was feeding well and was discharged on the $4^{\text {th }}$ post-operative day.

Intubating a child in the air or bringing the head beyond the edge of the table in children with swellings in the back of the neck has a definite role in improving the laryngoscopic view. Although this technique has been described earlier, ${ }^{[2-4]}$ we wish to highlight the importance of appropriate positioning during the management of challenging airways such as these. The availability of newer video laryngoscopes and different blades may prompt a novice to ignore the role of positioning during intubation. However, the key to a successful management of challenging airway is a combination of careful positioning and intubation skill which can only be complemented with the use of newer gadgets.

Paralysing a child using a non-depolarising muscle relaxant in the presence of a difficult airway is a controversial topic; since we were sure of mask ventilation and we were expecting prolonged scopy time, we wanted to select atracurium rather succinylcholine. In case of a failed intubation scenario, we had a backup plan of placing a laryngeal mask airway and ventilating the child or a video laryngoscopic-assisted flexible fiberoptic intubation.

Positioning the child without causing undue pressure on the meningocele (in supine position) and face or trunk (in prone position) can be done safely using commonly available equipment tailored to the patients' need. Use of a Maquet pillow for positioning the child during intubation has been described by Yuldurm et al ${ }^{[3]}$ In our case, the routinely used Maquet pillow was modified and used for both supine and prone position. Careful planning and preparation are more important in these cases to avert an accidental rupture of the encephalocele before surgery.
The technique of reinforcing the smaller ETT with a slitted larger ETT (1 mm more) is an easy way to buttress the smaller ETT and making it kink free, especially when the airway is close to the surgical field or if the child is to be positioned prone or lateral. An additional advantage of this technique is that it can be done at any time either before or after intubation.

Although none of these techniques are innovative or unique by themselves, thoughtful and meticulous planning is required in the anaesthetic management of these extremely fragile neonates. Proceeding to anaesthetise these children without adequate back up plans for every anticipated potential problem may initiate a cascade of events which may quickly progress into an emergency and culminate in a catastrophe since 'a chain is only as strong as its weakest link'.

\section{Financial support and sponsorship}

Nil.

\section{Conflicts of interest}

There are no conflicts of interest.

\section{REFERENCES}

1. Singh G, Mariappan R, Gautham AK. Buttressing the pediatric endotracheal tube in neonates: A simple but useful technique. J Neurosurg Anesthesiol 2017; Published ahead of Print. doi: 10.1097/ANA.0000000000000396.

2. Goel V, Dogra N, Khandelwal M, Chaudhri R. Management of neonatal giant occipital encephalocele: Anaesthetic challenge. Indian J Anaesth 2010;54:477-8.

3. Yuldurım ZB, Avci E, Torun F, Cengiz M, Cigdem A, Karabag H, et al. Airway management for occipital encephalocele in neonatal patients: A review of 17 cases. J Neurosci Rural Pract 2011;2:159-61.

4. Manhas Y, Chinnan NK, Singh AK. Neonatal airway management in occipital encephalocele. Anesth Analg 2006;103:1632.

This is an open access article distributed under the terms of the Creative Commons Attribution-NonCommercial-ShareAlike 3.0 License, which allows others to remix, tweak, and build upon the work non-commercially, as long as the author is credited and the new creations are licensed under the identical terms.

\begin{tabular}{|l|l|}
\hline \multicolumn{2}{|c|}{ Access this article online } \\
\hline Quick Response Code: & Website: \\
\hline & www.jnaccjournal.org \\
\cline { 2 - 2 } & \\
\hline
\end{tabular}

How to cite this article: Gautham AK, Mariappan R, Singh G. Lessons learnt in the anaesthetic management of a neonate with giant occipital meningomyelocoele. J Neuroanaesthesiol Crit Care 2017;4:127-8. 